University of Nebraska - Lincoln

DigitalCommons@University of Nebraska-Lincoln

$9-8-2020$

\title{
Financial Health of Grain Operations after Adding a Hog Barn
}

Elliott James Dennis

University of Nebraska - Lincoln, elliott.dennis@unl.edu

Follow this and additional works at: https://digitalcommons.unl.edu/ageconfarmmgmt

Part of the Agribusiness Commons, Entrepreneurial and Small Business Operations Commons, Management Information Systems Commons, Other Animal Sciences Commons, Other Business

Commons, and the Other Economics Commons

Dennis, Elliott James, "Financial Health of Grain Operations after Adding a Hog Barn" (2020). Extension Farm and Ranch Management. 52.

https://digitalcommons.unl.edu/ageconfarmmgmt/52

This News Article is brought to you for free and open access by the Agricultural Economics Department at DigitalCommons@University of Nebraska - Lincoln. It has been accepted for inclusion in Extension Farm and Ranch Management by an authorized administrator of DigitalCommons@University of Nebraska - Lincoln. 


\title{
Financial Health of Grain Operations After Adding a Hog Barn
}

\author{
Dr. Elliott J. Dennis, Assistant Professor \& Livestock Extension Economist \\ Department of Agricultural Economics, University of Nebraska - Lincoln
}

This article was first published by Nebraska Pork Talk.

There is strong local and national interest in adding hog barns to existing row crop operations. Declining on farm income over the past several years has accelerated this interest. Grain operations cite diversifying farm income, adding another family to the farm operation, and/or replace commercial fertilizer expense as the primary reasons for adding a hog barn.

While there is industry demand to increase hog contract growing, these agreements can possess significant benefits and risks to producers. This is the second of a four part series which will discuss some financial and legal implications of adding a hog barn to an existing grain operation. In this second part, I discuss how the financial health of grain operations potentially changed after adding a hog barn. These financial metrics are compared against operations that only raise grain and operations that only raise hogs. Various financial metrics typically used by lenders, accountants, and other professionals to assess the financial health of agricultural operations are used to make comparisons.

\section{Financial Health After Adding Hog Operation to Existing Grain Operation}

One of the primary questions that needs to be addressed is how the financial stability of an existing grain operation is affected if a hog operation is added. To address this question, I compare the financial stability of grain only operations, hog only operations, and grain + hog operations. Data was collected from FINBIN and Nebraska Farm Business databases. I restrict my analysis to grain, hog, and grain + hog operations located in the Northern Plains from 2008 to 2018.

Several limiting factors should be noted that condition these conclusions. First, there is no complete way to separate out the type of hog operation that was added. Hence, hog operations could range from anything from sow barns to finishing barns. Second, I do not observe enough farm and livestock operations in Nebraska over time so I focus on all operations throughout the Northern Plains. I know the structure of these operations varies by location but I am unable control for this. Third, I do not know the type of grain operation and hence these findings are not specific to a given crop (i.e. corn, soybean, or wheat operations). These results could vary by the type of grain operation given that some crops require more/less capital investment. Fourth, ideally, I would observe the specific year grain operations added a hog operation and then compare financial stability both pre and post adoption. This would cleanly illustrate the effect that the hog barn decision had on a grain operation financial stability. However, I only observe different grain, hog, and grain + hog operations over time with not indication of how long a hog barn has been operating.

Given the limitations listed above, I focus on four key areas of farm financial stability - liquidity, profitability, efficiency, and repayment capacity. Within these four areas I selected six different 
metrics. Figure 1 summarizes these six key metrics for grain, hog, and grain + hog operations between 2008 and 2018. The left panel is the mean value across all farms for a given financial measure. The right panel is the coefficient of variation $(\mathbf{C V})$ and tells us how much uncertainty there is for a given measure. A larger CV value implies more variation (i.e. uncertainty) where greater variation/uncertainty is perceived as less desirous. The key findings across the financial measures is as follows.

\section{Liquidity: Current ratio}

The current ratio represents an operations ability generate enough cash flow for family living, taxes and debt payments. Greater than 2.0 is considered strong, 2.0 to 1.3 would fall in the caution range, and less than 1.3 would be vulnerable. On average, all three operations are have strong current ratios. Thus, the current ratio for grain operations is no different than grain + hog operations but there greater uncertainty in our measure for grain + hog operations compared to grain operations.

\section{Profitability: Rate of return on assets (cost) and Operating profit margin}

The rate of return on assets measured at cost can be viewed as the interest rate an operation earned in the past year on all money invested in the business. Earning greater than 8 percent is considered strong, between 4 and 8 percent is the caution range, and less than 4 percent is considered vulnerable. On average, both grain and grain + hog operations earned a strong rate of return on assets between 2008 and 2018 and grain + hog is slightly lower. Thus, adding a hog operation marginally decreases the rate of return but we are more certain about that rate of return.

The operating profit margin is a measure of the operating efficiency of the business. Effectively it measures how operations are controlling operating expenses relative to the value of its output. Margin greater than 25 percent is considered strong, 25 to 15 percent is considered in the caution range and less than 15 percent is vulnerable. Both the grain and grain + hog operations are in the caution area. Most importantly, there is no major difference between grain and grain + hog operations and there is no major difference in the certainty of this measurement.

\section{Efficiency: Asset turnover rate (cost) and Interest expense ratio}

The asset turnover rate measured at cost is a measure of the efficiency of using capital. The asset turnover rate and operating profit margin are used together to determine the rate of return on assets (i.e. rate of return on assets $=$ operating profit margin $\times$ asset turnover rate) or level of profitability for an operation. An asset turnover rate (cost) greater than $25 \%$ is considered strong, 25 to $15 \%$ is considered in the caution range, and less than $15 \%$ is vulnerable. All operations are extremely strong in their ability to efficiently use capital. Grain + hog operations are slightly less efficient than grain operations and more efficient then hog operations. However, we are more certain about obtaining this value under a grain + hog operation compared to a grain operation.

The interest expense ratio is one of four key rations that tell about the distribution of gross income. A larger expense ratio implies a greater amount of gross income being paid for interest. An operation with less than 5\% is strong, 5 to $10 \%$ should be cautious, and greater than $10 \%$ is 
vulnerable. All three operations have interest expense ratios that are considered cautious. On average, grain operations pay more gross income towards interest than grain + hog and hog operations but we are less certain of this value for grain + hog than grain operations.

\section{Repayment Capacity: Term debt coverage ratio}

Term debt coverage ratio is a key metric used to determine whether an operation produced enough income to cover all intermediate and long-term debt payments. A term debt coverage ratio greater than 1.75 is considered strong, 1.25 to 1.75 is considered in the caution range, and less than 1.25 is considered to be vulnerable. Both grain and grain + hog operations were in the caution range. However, grain + hog operations were slightly lower implying they are marginally more stressed to repay debt but we are less certain of this value.

\section{Summary}

In summary grain and grain + hog operations did not significantly affect the operations liquidity, profitability, efficiency, and repayment capacity. While there were slight differences, none of these differences were large enough to modify the risk profile of the operation. Likewise, for most key financial metrics there was a similar amount of certainty in values. Greater uncertainty would imply that the values change dramatically from year to year. These findings should be interpreted within the context of the limitations 

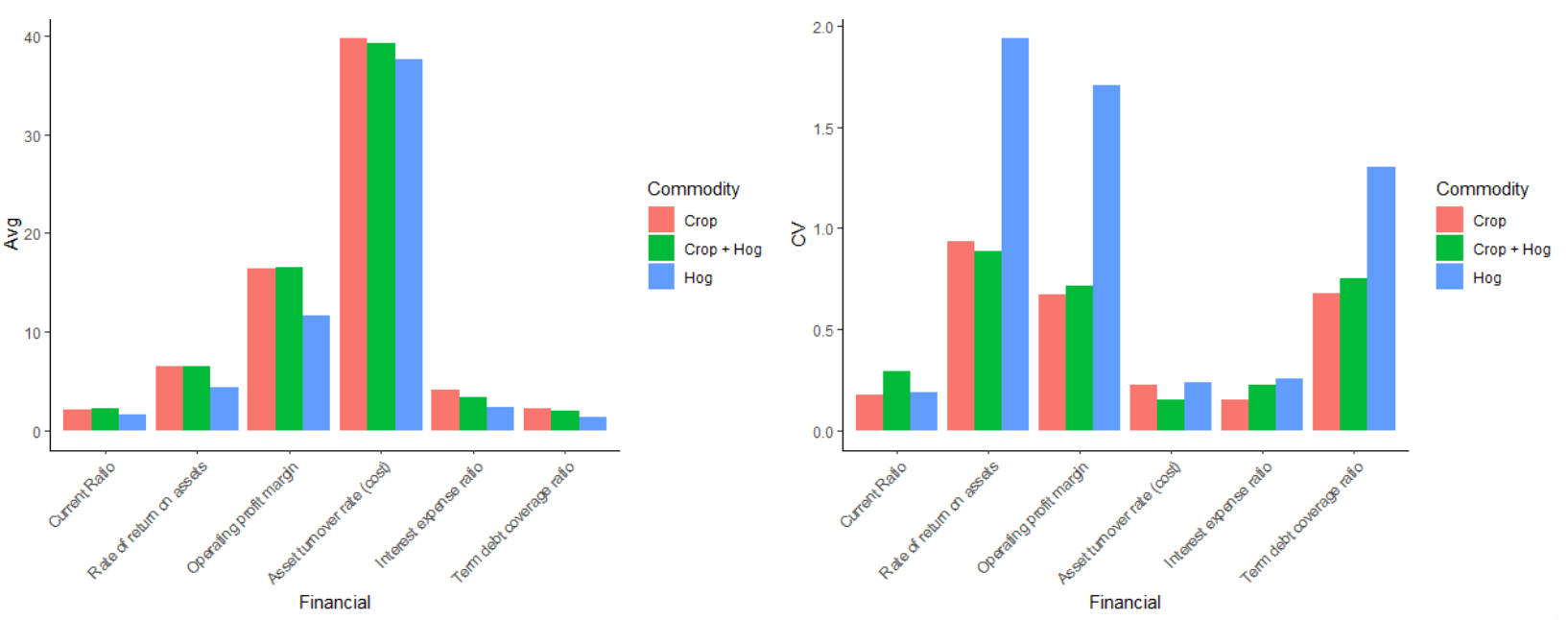

Figure 1. Key Farm Financials Across Different Northern Plains Agricultural Operations, 2008-2018

Notes: Crop and hog operations include all types of operations and contract agreements for operations in the Northern Plains between 2008 and 2018. Left panel displays the mean value by type of operation between 2008 and 2018. The coefficient of variation (CV) divides this mean by the standard deviation and is a general measure for uncertainty. Higher levels of CV imply greater uncertainty from year to year.

Source: FINBIN and Nebraska Farm Business databases (2008-2018) 